\title{
Laboratory and in situ damage evaluation of geogrid used in asphalt concrete pavement
}

\author{
Cyrille Chazallon ${ }^{1}$, J. Van Rompu' ${ }^{2}$, M. L. Nguyen ${ }^{3}$, P. Hornych ${ }^{3}$, S. Mouhoubi ${ }^{1}$, D. \\ Doligez $^{4}$, L. Brissaud ${ }^{2}$, Y. Le Gal ${ }^{2}$, E. Godard ${ }^{2}$ \\ ${ }^{1}$ ICUBE, UMR 7357 CNRS, Université de Strasbourg, INSA de Strasbourg, France, \\ ${ }^{2}$ Colas S.A., Magny les Hameaux, France \\ ${ }^{3}$ IFSTTAR, Nantes, France \\ ${ }^{4} 6 \mathrm{D}$ Solutions, Sainte Foy Les Lyons, France \\ Corresponding author: cyrille.chazallon@insa-strasbourg.fr
}

\begin{abstract}
We present in this paper, the damage evaluation of 9 different types of geogrids which have been recovered from laboratory asphalt compacted slabs and in situ test sections of asphalt concrete pavements. After pavement construction, the geogrids have been recovered from different locations on the field sections, and their residual mechanical properties have been evaluated in the laboratory. The same tests have been performed for recovered grids from laboratory compacted slabs. Different compaction processes have been applied for a simulated semi-coarse asphalt concrete made with a petroleum oil to the same hot mixed asphalt which has been used in situ. For the compaction, a wheel tracking device which provides a free rolling and mimics the rubber tired rollers or a compaction damaging device being more representative of on site steel rollers has been used.

The tensile strength, stiffness modulus and fatigue strength of each yarn of the grids recovered from test sections have been measured. The main results are that, if the tensile strength is decreased by the compaction process, the stiffness modulus remains practically unaffected and we can observe a clear influence of the grid coating on the tensile strength and modulus. Finally, tensile fatigue tests on recovered warp or filling yarns have been carried out, proving that, even if the grid is damaged during the compaction process, its endurance limit, even if it is decreased compared to virgin warp yarns, remains over the asphalt concrete fatigue limit.
\end{abstract}

Keywords : asphalt concrete, geogrid, damage evaluation, residual properties

\section{Introduction}

To ensure an efficient reinforcement, and a reliable design of a pavement incorporating a grid, it is required to know the residual mechanical properties of the geogrid after its implementation and compaction of the above asphalt concrete layer and the level of damage of the grid. Very few studies have been carried out on recovered grids used in asphalt concrete pavements; in [1] polyester or polypropylene geogrids have been recovered which are no more used in asphalt concrete (AC) pavement due to either the 
loss of their mechanical properties at the hot mixed asphalt temperature or their too stiff behavior which create an interface in the pavement. Nowadays the main grids which are used for pavement reinforcement are cost effective grids made of glass fibers. We present the results of the national French project SolDuGri [2] dealing with the damage process when they are used in AC pavement. In this project, laboratory compaction tests and full scale tests have been performed to evaluate the in situ damage of geogrids under a hot mixed asphalt (HMA) layer, occurring during its compaction in laboratory and in asphalt concrete pavements. Nine different geogrids have been tested with laboratory compaction process and four of these nine grids have been used in test sections with two different compacted asphalt concrete layers above. After construction, the geogrids have been recovered on the field sections, where they had been subjected to compaction only, or also to construction traffic, and their residual mechanical properties have been evaluated: residual strength, stiffness modulus and fatigue tensile strength.

\section{Materials used}

\subsection{Semi coarse asphalt concrete materials}

For the tests, two asphalt concrete materials have been chosen, for some laboratory tests and full scale test sections, a standard semi coarse asphalt concrete (SCAC) has been chosen. This formula has been used in the traditional hot mix version and as a warm mix $\mathrm{AC}$ in order to study the effect of the temperature on the glass geogrid reinforcement. The aggregates are from the gneiss quarry of Bréfauchet in Chéméré (LoireAtlantique, France), they are $100 \%$ crushed aggregates (Los Angeles and micro Deval between 22 and 23, flakiness index between 10 and 15). This SCAC is an "AC 10 surf 35/50". These asphalt concretes have been used in their usual range of thickness 5 to 7 $\mathrm{cm}$ for test sections. The tack coat between the asphalt layers was a classical cationic rapid setting bitumen emulsion, classified as C69B3.

The second one is a simulated semi-coarse asphalt concrete $(0 / 10)$, composed with diorite aggregates from La Noubleau quarry, close to Bréfauchet quarry, with the same particle size distribution and resistance characteristics (Los Angeles and micro Deval between 22 and 23, flakiness index between 10 and 15). A petroleum oil has been used, its viscosity at laboratory temperature $\left(\approx 22^{\circ} \mathrm{C}\right)$ is close to the one of bitumen at mixing temperature. Thus, the simulated AC behaves like a conventional HMA during the compaction phase. It allows to reproduce the damage occurring during this process at room temperature and to remove easily the grids afterwards, as the mix never turns to a cohesive block [3].

\subsection{Glass fiber grids}

Nine different grids made of glass fiber have been tested. For the full scale test sections and some laboratory compaction tests, four different grids, made of glass fiber coated 
with two different resins, of different stiffness, have been chosen for the study. The first two grids (G1 and G2) have a strength of $20 \mathrm{kN} / \mathrm{m}$ for a strain of $1 \%$, and are coated with a soft resin and a stiff resin, respectively. The two other grids (G3 and G4) have a $40 \mathrm{kN} / \mathrm{m}$ strength, and different, soft and stiff resins. For comparison purpose, the resistance to damage of 5 others glass fiber grids (G5 to G9), which could not have been used during the full-scale experimentation, is also assessed. The nominal tensile strengths at $1 \%$ strain of these 5 geogrids are 20 or $40 \mathrm{kN} / \mathrm{m}$. As shown in Tab. 1, three of these grids are coated with products (emulsified bitumen, elastomer and polymer) which differs from the resins of G1 to G4, whereas the two others grids are uncoated.

Table 1: Glass fiber grids characteristics (G1 to G9).

\begin{tabular}{cccccc}
\hline Grid & G1 & G2 & G3 & \multicolumn{2}{c}{ G4 } \\
\hline $\begin{array}{c}\text { Tensile strength at } 1 \% \\
(\mathrm{kN} / \mathrm{m})\end{array}$ & 20 & 20 & 40 & \multicolumn{2}{c}{40} \\
$\begin{array}{c}\text { Coating } \\
\text { Mesh size }(\mathrm{mm} 2)\end{array}$ & $\begin{array}{c}\text { Stiff resin } \\
40 * 40\end{array}$ & $\begin{array}{c}\text { Soft resin } \\
40 * 40\end{array}$ & $\begin{array}{c}\text { Stiff resin } \\
40 * 40\end{array}$ & \multicolumn{2}{c}{$\begin{array}{c}\text { Soft resin } \\
40 * 40\end{array}$} \\
\hline Grid & $\mathrm{G} 5$ & $\mathrm{G} 6$ & $\mathrm{G} 7$ & $\mathrm{G} 8$ & $\mathrm{G} 9$ \\
\hline $\begin{array}{c}\text { Tensile strength at } 1 \% \\
(\mathrm{kN} / \mathrm{m})\end{array}$ & 40 & 40 & 20 & 40 & 20 \\
Coating & $\begin{array}{c}\text { Emulsified bi- } \\
\text { tumen }\end{array}$ & Elastomer & Polymer & None & None \\
Mesh size $(\mathrm{mm} 2)$ & $40 * 40$ & $25 * 25$ & $25 * 25$ & $40 * 40$ & $23 * 23$ \\
\hline
\end{tabular}

\section{Laboratory direct tensile tests on recovered grids from slabs}

The resistance of geogrids subjected to compaction damage was evaluated during a laboratory tests campaign. The assessment principle remains identical: after the compaction simulation, warp yarns are extracted from removed grids and are subjected to direct tensile tests. The results are expressed through residual tensile strength and stiffness modulus ratios, compared to virgin yarns. Two compaction devices have been used in this part (Tab. 2), the first one is the MLPC (Matériel des Laboratoires des Ponts et Chaussées) slab compactor. It simulates the compaction process of rubber-tired rollers with free rolling. The other compaction device is the Cooper steel roller, which is more representative of on-site vibrating steel rollers.

Table 2: Laboratory compaction tests program.

\begin{tabular}{|c|c|c|}
\hline \\
\hline & MLPC slab compactor & Cooper steel roller \\
\hline HMA (Bréfauchet SCAC) & None & G3 \\
\hline Simulated AC & G1 & G1 to G9 \\
\hline
\end{tabular}

Residual tensile strength: the results obtained on residual tensile strengths during laboratory compaction test are plotted on Fig. 1. The comparison between the two 
compaction devices can be made trough the case of G1 geogrid. Results show that MLPC slab compactor is less aggressive than Cooper steel roller, the RTS (residual tensile strength) is respectively $84 \%$ and $66 \%$. It can be explained by the displacements of the aggregates on the yarns during the compaction which are circular and small with rubber-tired rollers, reminding a kneading process, whereas they are linear and large when a steel roller is used, generating a bigger damage. We can also identify the effect of the mix temperature by focusing on the G3 grid results, where tests with the same compaction device (Cooper steel roller) and both HMA and simulated AC at room temperature have been carried out on this grid. The RTS obtained is respectively $69 \%$ with petroleum oil-based asphalt concrete and $38 \%$ with hot SCAC. A damage induced by the temperature of the mix, which can affect the coating, is possible. The role of tack-coat can also be questioned: because it strongly bonds the grid to the layers, it makes the recovering harder. A potential over damaging may occur during this phase.

As expected, the coating seems to play a major role in the resistance of the grid. G8 and G9, the two uncoated grids of the experimental campaign, present significatively lower resistances than the other grids: their residual tensile strengths are 36 and $27 \%$ respectively, whereas the mean value for all coated grids is $68 \%$. Coating appears to be essential for the protection of the warp yarns against installation damage.

The differences between all the coated grids may also be explained by the type of coating, but others parameters such as the shape of the yarns, the grid aperture or the assembly method of the grid, not sudied here, can be considered. It explains why G1 and G3 grids, coated with the same stiff resin, present similar residual tensile strength (66 and $69 \%$ respectively), but not G2 and G4 grids ( 82 and 56\%), even though they are coated with the same soft resin.

Residual stiffness modulus: the residual stiffness modulus tests have been performed using a local extensometer in the small stress range (mean value of 3 cycles between $100 \mathrm{~N}$ and $1000 \mathrm{~N}$ ). We observe that the losses of stiffness modulus of coated grids are limited (from 3 to $14 \%$ ), whatever the considered test. It suggests that, even if the tensile strength of coated grids may be lowered by the compaction process, their mechanical properties remain nearly identical. Thus, it can be assumed that their structural contribution to the pavement reinforcement is not affected by installation damage. It is not the case for uncoated grids: the values of residual stiffness modulus of grids G8 and G9 are only 71 and $55 \%$, which is very low compared to coated grids. They seem to have suffered major deteriorations which lowered their properties: it raises serious doubts about their on-site effectiveness.

\section{Full scale test section}

A 15 meters long test section built on an existing subgrade with a load-bearing capacity higher than $100 \mathrm{MPa}$, (Soldugri project), has been devoted to the study of grid damage 
after construction. This section included the four different types of geogrids (G1, G3, $\mathrm{G} 2$ and G4). Four SCAC layers, each $5 \mathrm{~cm}$ thick have been laid one after the other to constitute the pavement test section. Void content measurements by a Troxler device on the surface of the 2nd and 4th layers indicate mean void contents of $5.7 \%$ and 5.8 $\%$ respectively on sections made of hot mix and $6.7 \%$ and $7.1 \%$ on the section made of warm mix. The different geogrids have been placed on the surface of the second SCAC layer. To study the effect of different surface conditions on the damage of the geogrids, on one half of the section, the surface of the second SCAC layer was milled, before placing the grids (to simulate the reinforcement of an old pavement - (noted surface B), and the second part was compacted normally, to simulate a new construction (noted surface A). The full scale test sections have been built using standard roadworks equipment as used on real construction sites.

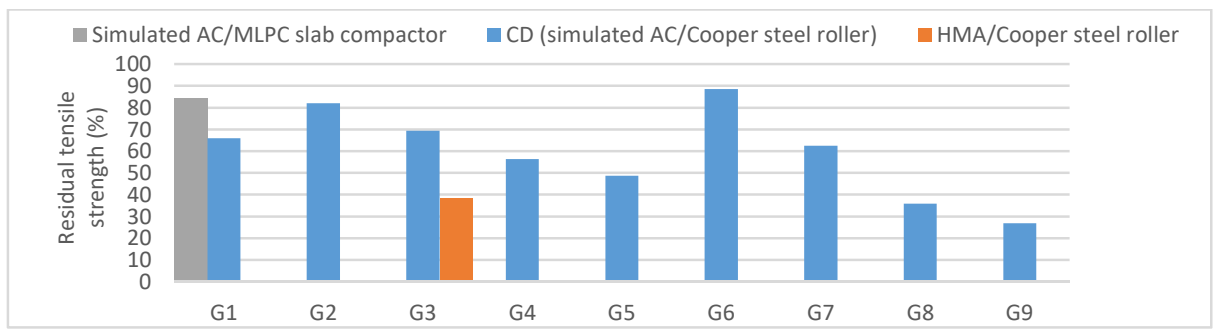

Fig. 1: Residual tensile strength of warp yarns after laboratory compaction tests, compared with tensile strength of virgin yarns.

Tests on recovered grids: in total, 32 grid sections $\left(64 \mathrm{~cm}^{2}\right)$ have been placed in the test section and 24 have been tested till now (361 yarns). Each section is trafficked on more than $50 \%$ of its surface by the wheels or the caterpillars of the finisher. This means that for the tension tests, slightly less than $50 \%$ of the yarns have been damaged only by the compaction, and a little more than $50 \%$ by both compaction and trafficking by the caterpillars or the wheels. During recovery, the loading received by each grid has been carefully identified, and three different loading processes have been distinguished : grids subjected only to compaction of the upper layers, without any other loading (no loading -NL), grids subjected to compaction and to loading by the wheels of the asphalt truck (T), grids subjected to compaction and loading by the finisher's caterpillars (C).

Residual tensile and fatigue (not presented here) strength: Fig. 2 compares the average residual tensile strength of each warp yarn type with all loading conditions and considering all types of surface A and B. We can observe that the coefficient of variation is rather large for all grids and that for all grids (except G4 and to a lesser extent G2), cumulative loadings have an influence on the residual strength, and the grid which has the softer resin $(\mathrm{G} 2)$ has relatively a higher residual strength than the stiffer one (G1), the results are inversed for the stiffer one G4 and G3. Finally, the warp yarns lying on a milled surface have a higher residual tensile strength than on a new surface. We think that the ripples on the milled surface give better protection compared with a new surface. This could be explained by the effect of the tack coat at the interface, 
which could preferentially fill the hollow grooves made by the milling, which are in the warp yarn direction. It can be underlined that this result is within the same range as the CD laboratory compaction tests described in a previous section (Fig. 1) for HMA Cooper steel roller.

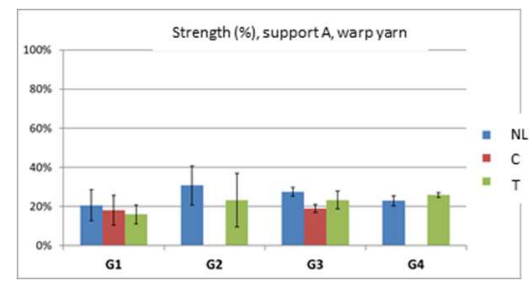

(a)

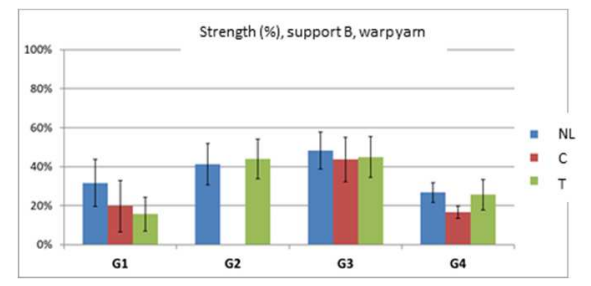

(b)

Fig. 2: Residual tensile strength of warp yarns for a new layer under the grids (a) and for milled surface under the grids (b) submitted to each type of loading.

The filing yarns give similar results (not shown in this paper) where the residual peak strength is improved for all grids. These results depend on the grid aperture, the coating strength and amount which can be different in each yarn direction.

\section{Conclusion}

During their installation in a pavement, geogrids can suffer from physical damage due to mechanical and thermal loads. Currently, this damage is not quantified, and not taken into account in design. These results also indicate that the level of damage depends on the thickness of the grids, and also on the type of resin coating protecting the yarns.

\section{Acknowledgments}

The work presented in this article was sponsored by the French National Research Agency (ANR-SolDuGri project ANR-14-CE22-0019).

\section{References}

1. J. Norambuena-Contreras, I. Gonzalez-Torre, D. Fernandez-Arnau, C. Lopez-Riveros, Mechanical damage evaluation of geosynthetics fibres used as anti-reflective cracking systems in asphalt pavements. Construction and Building Materials, 109, 47-54, 2016

2. Chazallon C., Barazzutti C., Pelletier H., Nguyen M.L., Hornych P., Mouhoubi S., D. Doligez (2020) Reproduction of Geogrid In Situ Damage Used in Asphalt Concrete Pavement with Indentation Tests. Journal of Testing and Evaluation, 48:1.

3. J. Van Rompu, E. Godard, L. Brissaud, E. Loison, Procédé de renforcement d'enrobés Colgrill R qualification des grilles en laboratoire et exemple de réalisation, Revue Générale des Routes et des Aérodromes, 944, Mars 2017 